AQUINO, L.A.; PUIATTI, M.; PEREIRA, P.R.G.; PEREIRA, F.H.F.; CASTRO, M.R.S.; LADEIRA, I.R. Características produtivas do repolho em função de espaçamentos e doses de nitrogênio. Horticultura Brasileira, Brasília, v.23, n.2, p.266-270, abr-jun. 2005.

\title{
Características produtivas do repolho em função de espaçamentos e doses de nitrogênio
}

\author{
Leonardo A. de Aquino'; Mário Puiatti'; Paulo R.G. Pereira ${ }^{1}$; Francisco H.F. Pereira'; Mariana R.S. \\ Castro $^{1}$; Igor R. Ladeira ${ }^{1}$ \\ ${ }^{1}$ UFV, Depto. Fitotecnia, 36570-000 Viçosa-MG; E-mail: mpuiatti@ufv.br
}

\begin{abstract}
RESUMO
Avaliou-se características produtivas do repolho 'Kenzan', em função de espaçamentos ( 80 × 30; 60 × 30 e 40 × 30 cm) e doses de $\mathrm{N}\left(0 ; 75 ; 150 ; 225\right.$ e $\left.300 \mathrm{~kg} \mathrm{ha}^{-1}\right)$. O experimento foi conduzido em condições de campo, em solo com baixo teor de $\mathrm{N}$, de setembro a dezembro/2002. Utilizou-se o delineamento inteiramente casualizado, esquema de parcelas subdivididas, com quatro repetições, tendo os fatores espaçamentos e doses de $\mathrm{N}$ nas parcelas e subparcelas, respectivamente. As doses de N foram parceladas: $20 \%$ no transplante e aos 20 dias após o transplante (DAT) e 30\% aos 35 e aos 50 DAT. A colheita iniciou-se aos 65 e estendeu-se até aos 83 DAT. Foram avaliadas a produção de massa fresca de cabeças/área, massa fresca média de cabeça, área foliar das folhas externas à cabeça, índice de área foliar, precocidade de colheita e renda líquida. Com o aumento das doses de $\mathrm{N}$ observou-se aumento de todas as características avaliadas, enquanto que com a redução dos espaçamentos observou-se diminuição da massa fresca média de cabeça. Para área foliar externa à cabeça e precocidade de colheita, a redução foi significativa apenas com uso das maiores doses de $\mathrm{N}$. Considerando a produção de massa fresca de cabeças/área, a massa fresca média de cabeça adequada às exigências do mercado e dos consumidores brasileiros e a renda líquida obtida, o espaçamento de $40 \times 30 \mathrm{~cm}$ e a dose de $253 \mathrm{~kg} \mathrm{ha}^{-1}$ de $\mathrm{N}$ foram os mais indicados para o cultivo do repolho no período de primavera.
\end{abstract}

Palavras-chave: Brassica oleracea var. capitata, população, fertilização nitrogenada, produção.

\begin{abstract}
Production of cabbage with relation to spacing and doses of nitrogen

Yield of 'Kenzan' cabbage was evaluated under plant spacing $(80 \times 30 ; 60 \times 30$ and $40 \times 30 \mathrm{~cm})$ and doses of $\mathrm{N}(0 ; 75 ; 150 ; 225$ and $300 \mathrm{~kg} \mathrm{ha}^{-1}$ ). The experiment was conduced in field conditions, using a soil with low N content, from September to December/2002. The experimental design was a completely randomized split-pot scheme and four replicates, where the factors spacing and doses of $\mathrm{N}$ were in the plot and split-plot, respectively. The doses of $\mathrm{N}$ were applied using $20 \%$ of the total in the transplant and $20 \%$ at 20 days after the transplant (DAT) and 30\% at 35 and 50 DAT. Harvest began 65 DAT and extended to 83 DAT. Production of fresh mass of head/ area, mass fresh average weight of head, leaf area of external leaves, leaf area index, harvest precocity and liquid income were evaluated. Increasing the doses of $\mathrm{N}$ resulted in an increase of all the appraised characteristics. Reduction of spacing resulted in a decrease of the mass fresh average of head, leaf area of the external and crop precocity. Considering the production of fresh mass of head/area, the mass fresh average of head adapted to the demands of the market and of the Brazilian consumers and liquid income, the spacing of 40 x $30 \mathrm{~cm}$ and the dose of $253 \mathrm{~kg} \mathrm{ha}^{-1}$ of $\mathrm{N}$ proved to be the most suitable for the cultivation of the cabbage in spring conditions.
\end{abstract}

Keywords: Brassica oleracea var. capitata, population, nitrogen fertilization, yield.

\section{(Recebido para publicação em 26 de março de 2004 e aceito em 27 de novembro de 2004)}

$\mathrm{O}$ repolho (Brassica oleraceae var. capitata) é uma planta herbácea, folhosa, com grande versatilidade, não somente pelo seu valor nutritivo, sobretudo cálcio proteína e vitamina $\mathrm{C}$, constituindo-se em alimento de excelente qualidade para grande parte da população (FILGUEIRA, 2000; LÉDO et al., 2000), mas pelo seu caracter social por ser uma cultura em que se utiliza muita mão-de-obra, sendo cultivada essencialmente por pequenos agricultores (SILVA JÚNIOR, 1987; SILVA JÚNIOR et al., 1988; FILGUEIRA, 2000).

A qualidade dos produtos e a conservação do meio ambiente também devem se constituir em objetivos da agricultura quando da busca por aumento em produtividade e redução dos cus- tos (PACHECO, 1996; TORRES, 1999). Dentre os fatores que mais influenciam a produtividade de diversas culturas está o número de plantas/área. Aumento no número de plantas/área promove redução da massa fresca média das plantas e, dentro de certos limites, aumento da produtividade em culturas como brócoli, repolho, alface e couve-da-malásia (THOMPSON; TAYLOR, 1976; STOFFELLA; FLAMING, 1990; BORA et al., 1992; SILVA et al., 2000; FERREIRA et al., 2002).

Para o repolho, os espaçamentos mais recomendados e/ou utilizados, variam de 70-80 cm entre linhas e de 30$50 \mathrm{~cm}$ entre plantas (PACHECO, 1996; RIBEIRO et al., 1999; FILGUEIRA, 2000; LÉDO et al., 2000). O ajuste de espaçamento faz-se necessário para cada cultivar para se evitar que a área foliar, importante no fornecimento de fotoassimilados, seja afetada de forma a prejudicar a produtividade (CASTRO et al., 1987; FERREIRA et al., 2002). Além disso, a utilização de espaçamento adequado proporciona produção de "cabeças" mais compactas, de menor massa média (1,0 a 1,5 kg), mais exigidas pelo mercado consumidor brasileiro (SILVA JÚNIOR, 1987; SILVA JÚNIOR et al., 1988; LÉDO et al., 2000). Todavia, altas densidades de plantio aumentam o tempo necessário para atingir o ponto de colheita em couve-de-bruxelas (KIRK, 1981) e em repolho (STOFFELLA; FLAMING, 1990). Em estudos de espaçamento, a estimativa do índice de área foliar é importante pois indica o aproveitamento do 
espaço físico no solo a irradiância incidente e possíveis problemas com autosombreamento (CASTRO et al., 1987).

Com aumento no número de plantas/ área a fertilização também deve ser incrementada de modo a permitir o adequado crescimento das mesmas. No caso do repolho, o Né o segundo nutriente mais absorvido, sendo de grande importância para a produtividade e qualidade do produto (BORA et al., 1992; PACHECO, 1996; FILGUEIRA, 2000). Além do aspecto quantitativo (produção de biomassa) o $\mathrm{N}$ também interfere no aspecto qualitativo das culturas, principalmente de folhosas como o repolho, pois a disponibilidade excessiva no solo pode acumular na planta na forma de $\mathrm{NO}_{3}^{-}$; este, em altas concentrações, pode formar no organismo humano nitrosaminas carcinogênicas além de causar a metahemoglobinemia (TORRES, 1999; CHITARRA; CHITARRA, 1990). Além disso, o excesso de fertilização nitrogenada em algumas espécies pode prolongar o ciclo cultural, causar redução nos teores de açúcares e de vitamina $\mathrm{C}$ e propiciar o aumento da incidência de pragas e doenças (HAYNES, 1986; MARSCHNER, 1995; PACHECO, 1996; TORRES, 1999; FILGUEIRA, 2000). Portanto, os fatores população e dose de $\mathrm{N}$ devem ser avaliados em conjunto visando maximizar o uso do espaço físico, sem que os demais recursos sejam limitantes à cultura (BORA et al., 1992; MARSCHNER, 1995; CARDOSO; HIRAKI, 2001; RESENDE; SOUZA, 2001; FERREIRA et al., 2002).

O trabalho teve como objetivo avaliar o efeito de três espaçamentos entre linhas e de cinco doses de $\mathrm{N}$ sobre as características produtivas e de crescimento do repolho 'Kenzan' em cultivo de primavera.

\section{MATERIAL E MÉTODOS}

O trabalho foi desenvolvido na UFV, de setembro a dezembro/2002, utilizando-se o repolho híbrido 'Kenzan'. As mudas foram produzidas sob ambiente protegido, em bandejas de isopor de 128 células, preenchidas com substrato agrícola comercial recomendado para a cultura, enriquecido com $3 \mathrm{~kg} \mathrm{~m}^{-3}$ de superfosfato simples.

O solo da área experimental, classificado como Argissolo Vermelho Ama- relo, apresentou, na análise laboratorial, as características: $\mathrm{pH}$ em $\mathrm{H}_{2} \mathrm{O}=6,1 ; \mathrm{P}=$ $36 \mathrm{mg} \mathrm{dm}^{-3}, \mathrm{~K}=91 \mathrm{mg} \mathrm{dm}^{-3}, \mathrm{Ca}^{2+}=3,6$ $\mathrm{cmol}_{\mathrm{c}} \mathrm{dm}^{-3}, \mathrm{Mg}^{2+}=0,8 \mathrm{cmol}_{\mathrm{c}} \mathrm{dm}^{-3}, \mathrm{H}+\mathrm{Al}$ $=2,31 \mathrm{cmol} \mathrm{dm}^{-3}, \mathrm{SB}=5 \mathrm{cmol} \mathrm{dm}^{-3}, \mathrm{~V}$ $=68 \%, \mathrm{~m}=0 \%$ e M.O $=19,2 \mathrm{~g} \mathrm{~kg}^{-1}$. Anteriormente à instalação do experimento com a cultura do repolho realizaram-se vários cultivos sucessivos com milho, sem fertilização, objetivando reduzir os teores de $\mathrm{N}$ no solo.

Utilizou-se o delineamento experimental inteiramente casualizado, no esquema de parcelas subdivididas, com quatro repetições. As parcelas foram constituídas por três espaçamentos entre linhas $(80 ; 60$ e $40 \mathrm{~cm})$ e as subparcelas por cinco doses de $\mathrm{N}(0 ; 75 ; 150 ; 225 \mathrm{e}$ $300 \mathrm{~kg} \mathrm{ha}^{-1}$ de N). Cada subparcela foi composta por quatro fileiras com oito plantas espaçadas de $30 \mathrm{~cm}$ na linha, totalizando 32 plantas. Considerou-se útil as duas fileiras centrais excluindo-se 60 $\mathrm{cm}$ das extremidades.

O preparo do solo constou de uma aração, duas gradagens e abertura manual dos sulcos de plantio com auxílio de enxadas. Com exceção do N, as adubações com os demais nutrientes foram realizadas com base na análise química do solo e recomendações para a cultura no estado de Minas Gerais (RIBEIRO et al., 1999). Na adubação de plantio os nutrientes foram distribuídos e incorporados cinco dias antes do transplante das mudas, sendo aplicadas: $300 \mathrm{~kg} \mathrm{ha}^{-1}$ de $\mathrm{P}_{2} \mathrm{O}_{5} ; 36 \mathrm{~kg} \mathrm{ha}^{-1}$ de $\mathrm{K}_{2} \mathrm{O}$ e $20 \%$ da dose total de $\mathrm{N}$ de cada tratamento. Utilizouse como fontes de N, P e K, a uréia, o superfosfato simples e o cloreto de potássio, respectivamente. Aplicou-se ain$\mathrm{da}$, no plantio, o equivalente a $15 \mathrm{~kg} \mathrm{ha}^{-1}$ de sulfato de zinco, $10 \mathrm{~kg} \mathrm{ha}^{-1}$ de bórax, $10 \mathrm{~kg} \mathrm{ha}^{-1}$ de sulfato de cobre e $0,5 \mathrm{~kg}$ ha ${ }^{1}$ de molibdato de amônio. Aos 28 dias após a semeadura as mudas, com 4 a 5 folhas definitivas, foram transplantadas para o local definitivo. Três adubações de cobertura com $\mathrm{N}$ e $\mathrm{K}$ foram realizadas aos 20, 35 e 50 dias após o transplante (DAT) das mudas. Aos 20 DAT foram aplicados $20 \%$ da dose total de $\mathrm{N}$ e $36 \mathrm{~kg}$ $\mathrm{ha}^{-1}$ de $\mathrm{K}_{2} \mathrm{O}$ e nas duas posteriores $30 \%$ da dose total de $\mathrm{N}$ e $54 \mathrm{~kg} \mathrm{ha}^{-1}$ de $\mathrm{K}_{2} \mathrm{O}$.

Durante a condução do experimento realizaram-se duas capinas manuais aos 18 e 31 DAT. Aos 28 DAT foi reali- zada uma pulverização, à base de Deltametrina 2,5 E, para controle da traça das brássicas (Plutella xylostella). As irrigações foram realizadas por aspersão convencional, de acordo com a necessidade da cultura.

A colheita foi parcelada, realizada quando a compacidade (firmeza) das cabeças alcançavam a aceitação comercial, iniciando-se aos 65 DAT e estendendo-se até aos 83 DAT. Em cada subparcela foram colhidas seis plantas uniformes da área útil, que originaram os dados de massa fresca média de cabeça e produção de massa fresca de cabeça/área. Em duas dessas plantas, as folhas externas (saia) foram utilizadas para obtenção da área foliar externa à cabeça, obtida por meio do integrador de área foliar (Área Meter Licor-3100). $\mathrm{O}$ índice de área foliar (IAF) foi estimado dividindo-se a área foliar da planta pela respectiva área de solo disponível à mesma. A precocidade de colheita foi obtida pela média ponderada do número de plantas colhidas em cada colheita e as épocas da colheita. Realizou-se análise econômica considerando os custos com sementes, produção de mudas, preparo de solo, mão-de-obra, fertilizantes, produtos fitossanitários, irrigação, controle de plantas daninhas, embalagens, transporte e vendas nas doses de $\mathrm{N}$ estimadas para máxima eficiência econômica, considerada de $95 \%$ da produção máxima, de acordo com metodologia descrita por Fontes (2001), em cada espaçamento. Para tal, utilizouse os valores médios dos preços dos insumos e do repolho para venda praticados na CEASA-MG, CEASA-RJ e CEAGESP no período em questão, ressaltando porém, que esses custos e cotações podem variar conforme oferta, a demanda e as características do produto.

Os resultados obtidos foram submetidos à análise de variâncias utilizandose o programa estatístico SAEG (RIBEIRO JÚNIOR, 2001). Considerou-se dose de $\mathrm{N}$ como fator quantitativo, submetendo os dados à análise de regressão, e espaçamentos como fator qualitativo, neste caso comparando-se as médias pelo teste de Tukey a 5\% de probabilidade.

\section{RESULTADOS E DISCUSSÃO}

Houve interação espaçamentos $\mathrm{x}$ doses de $\mathrm{N}$ para todas as características 

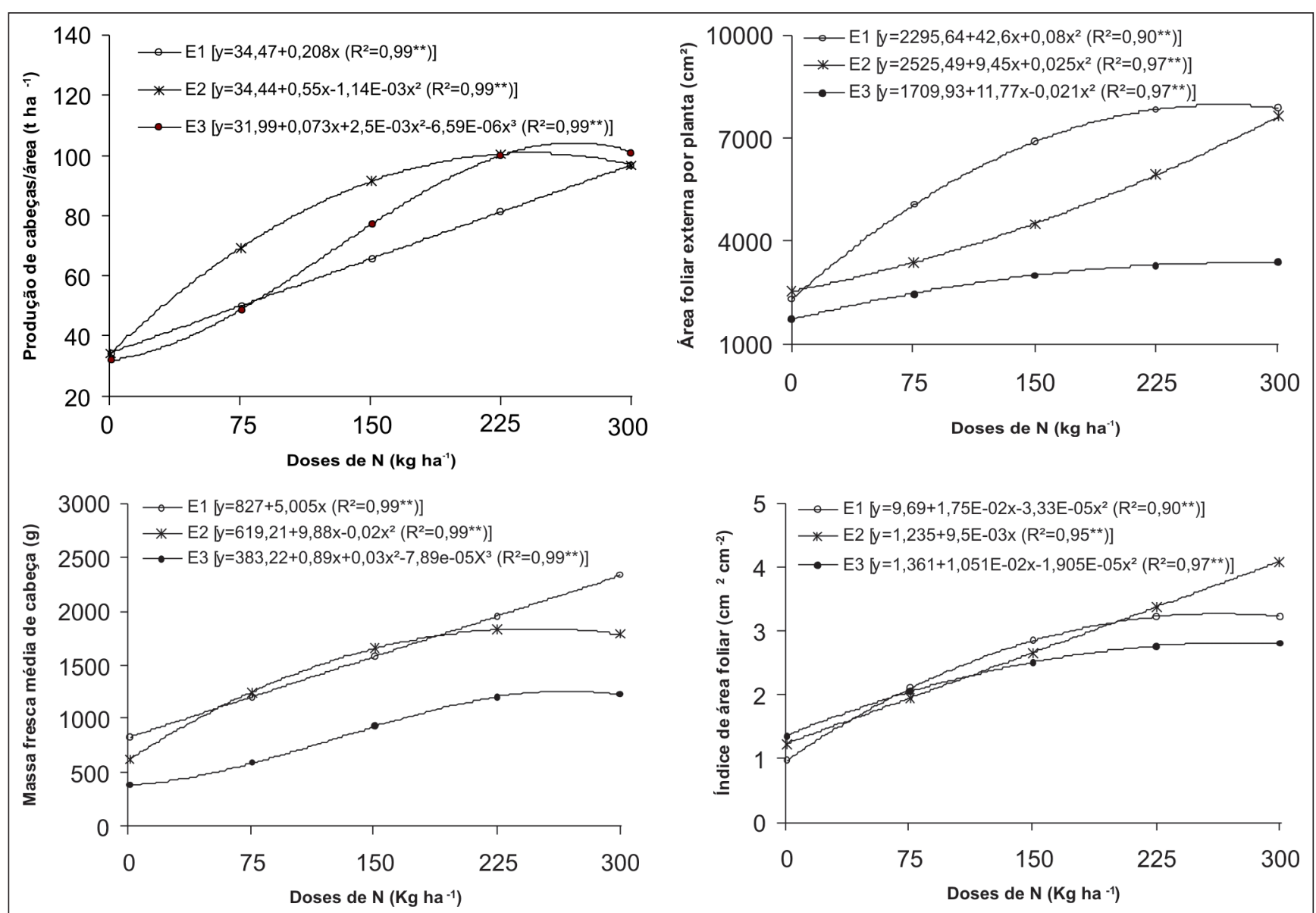

Figura 1. Produção de massa fresca de cabeça/área, massa fresca média de cabeça, área foliar externa à cabeça e índice de área foliar em função de doses de nitrogênio nos espaçamentos 80 x $30 \mathrm{~cm}$ (E1), 60 x $30 \mathrm{~cm}$ (E2) e 40 x $30 \mathrm{~cm}$ (E3). Viçosa, UFV, 2002.

de produção e de crescimento avaliadas. A produção de massa fresca de cabeça/ área aumentou com o incremento das doses de N (Figura 1), não havendo diferença entre espaçamentos na ausência e na maior dose de $\mathrm{N}$ aplicado (Tabela 1). As produções máximas estimadas de massa fresca de cabeça/área para $60 \mathrm{x}$ $30 \mathrm{~cm}$ (E2) e 40 x $30 \mathrm{~cm}$ (E3) foram de 100,77 e $104,27 \mathrm{t} \mathrm{ha}^{-1}$, obtidas com as doses de 241 e $267 \mathrm{~kg} \mathrm{ha}^{-1}$ de N, respectivamente. No espaçamento $80 \times 30 \mathrm{~cm}$ (E1) à resposta da produção foi linear até a dose de $300 \mathrm{~kg} \mathrm{ha}^{-1}$ de N (Figura 1). O incremento nas doses de N, ao proporcionar maior disponibilidade do nutriente às plantas, estimulou o crescimento do repolho, resultando em maior produção de massa fresca de cabeças/ área. A ausência de diferença de produção de massa fresca de cabeça/área entre espaçamentos na maior dose de $\mathrm{N}$, deveu-se possivelmente ao efeito compensatório do $\mathrm{N}$ disponível em maior quantidade às plantas no maior espaçamento, o qual estimulou seu crescimento, enquanto que na ausência de N o maior número de plantas/área no menor espaçamento teria promovido maior aproveitamento dos nutrientes no solo. Estes resultados estão de acordo com os encontrados por Bora et al. (1992) em repolho, por Cardoso e Hiraki (2001) em rabanete e Ferreira et al. (2002) em couve-da-Malásia.

A massa fresca média de cabeça também aumentou com incremento das doses de N (Figura 1) e diminuiu no menor espaçamento em todas as doses de N (Tabela 1). Para o espaçamento E3, apesar da menor massa fresca média de cabeça, a produção de massa de cabeça/área não diferiu do E1 e E2 nas doses de 0 e $300 \mathrm{~kg} \mathrm{ha}^{-1}$ de N (Tabela 1), graças ao efeito compensatório da maior população de plantas/área. Este comportamento também foi observado para outras culturas, onde a redução no espaçamento apesar de proporcionar diminuição na massa média de planta pode, até certo limite, aumentar a produção/área (STOFFELLA; FLAMING, 1990; BORA et al., 1992; SILVA et al., 2000; FERREIRA et al., 2002). A redução da massa fresca média de cabeça no menor espaçamento, sem diminuição da produção de massa fresca de cabeça/ área, é interessante ao produtor de repolho, pois permite obter cabeças com tamanho dentro dos padrões comerciais exigidos pelo mercado consumidor (cabeças com 1,0 a 1,5 kg de massa fresca), mantendo a produtividade por área, facilitando a comercialização e o escoamento da produção e alcançando melhores preços, sobretudo em períodos em que há maior oferta do produto.

A área foliar externa à cabeça aumentou com o incremento nas doses de N (Figura 1) e diminuiu com a redução do espaçamento entre fileiras nas maiores doses de $\mathrm{N}$ (Tabela 1). O aumento da área foliar, seguindo o incremento na dose de $\mathrm{N}$, deveu-se ao efeito promotor do N no crescimento (TAIZ; ZIEGER, 
1991; CARDOSO; HIRAKI, 2001; FERREIRA et al., 2002). Por outro lado, a redução do espaçamento entre plantas conduz à maior competição entre plantas pelos fatores de crescimento, fazendo com que estas permaneçam menores, associado ao menor espaço físico disponível limitando a expansão foliar (CASTRO et al., 1987). Nos espaçamentos E1 e E3, houve tendência à estabilização da área foliar nas maiores doses de N (Figura 1), sendo que as áreas foliares máximas estimadas foram obtidas com as doses de 266 e $287 \mathrm{~kg} \mathrm{ha}^{-1}$ de $\mathrm{N}$, respectivamente.

A estabilização da área foliar em E1, possivelmente deveu-se ao grande espaço disponível às plantas o que permitiu a expressão máxima do potencial genético do híbrido, em termos de expansão de área foliar, isso porque o espaço físico e a fertilização nitrogenada não foram fatores limitantes. Por outro lado, em E3, a estabilização e a menor área foliar externa à cabeça deveram-se ao maior número de plantas/área, cujo espaçamento reduzido promoveu maior competição entre as plantas por espaço e fatores de crescimento. Ferreira et al. (2002), estudando espaçamentos e níveis de fertilização em couve-daMalásia, atribuiu o menor crescimento em menores espaçamentos, ao maior sombreamento entre plantas e a maior competição por água e nutrientes. No espaçamento intermediário (E2), as plantas não expressaram todo o seu potencial genético, quando comparado ao espaçamento E1, devido à menor disponibilidade de $\mathrm{N}$, e não sofreram limitação por espaço físico e demais fatores de crescimento na mesma proporção que no espaçamento E3, apresentando assim, comportamento intermediário entre E1 e E3.

$\mathrm{O}$ índice de área foliar também aumentou com incremento das doses de $\mathrm{N}$ (Figura 1), todavia diferiu somente entre os espaçamentos E2 e E3 e na dose de $300 \mathrm{~kg} \mathrm{ha}^{-1}$ de N (Tabela 1). Isso indica que a elevada área foliar nos E1 e $\mathrm{E} 2$, em especial no E1, não trouxe vantagens para a cultura em termos de produção de massa fresca de cabeça decorrente do aumento da área foliar externa à cabeça. No menor espaçamento (E3), apesar da menor área foliar externa à

Tabela 1. Produção de massa fresca de cabeças/área, massa fresca média de cabeça, área das folhas externas à cabeça e índice de área foliar em função de espaçamentos dentro de doses de N na cultura do repolho. Viçosa, UFV, 2002.

\begin{tabular}{|c|c|c|c|c|c|}
\hline \multirow{2}{*}{ Espaçamentos } & \multicolumn{5}{|c|}{ Doses de $\mathbf{N}\left(\mathrm{kg} \mathrm{ha}^{-1}\right)$} \\
\hline & 0 & 75 & 150 & 225 & 300 \\
\hline & \multicolumn{5}{|c|}{ Produção de massa fresca de cabeças/área $\left(\mathrm{t} \mathrm{ha}^{-1}\right)$} \\
\hline E1 $(80$ x 30cm) & $34,25 \mathrm{a}$ & $48,98 \mathrm{~b}$ & $68,07 \mathrm{~b}$ & $81,25 \mathrm{~b}$ & 96,28 a \\
\hline E2 $(60 \times 30 \mathrm{~cm})$ & 34,68 a & 69,07 a & 90,07 a & 101,90 a & 96,11 a \\
\hline \multirow[t]{3}{*}{ E3 $(40 \times 30 \mathrm{~cm})$} & 31,35 a & $51,35 \mathrm{~b}$ & $73,44 \mathrm{ab}$ & 103,16 a & 101,56 a \\
\hline & \multicolumn{3}{|c|}{ CV1 $=17,91 \%$} & \multicolumn{2}{|c|}{ CV2=12,69\%. } \\
\hline & \multicolumn{5}{|c|}{ Massa fresca média de cabeça (g/cabeça) } \\
\hline E1 $(80$ x 30cm) & 821,65 a & 1163,35 a & $1633,55 \mathrm{a}$ & 1950,00 a & $2310,20 \mathrm{a}$ \\
\hline E2 $(60 \times 30 \mathrm{~cm})$ & 823,53 a & 1243,15 a & 1621,03 a & 1833,93 a & 1729,15 b \\
\hline \multirow[t]{3}{*}{ E3 $(40 \times 30 \mathrm{~cm})$} & $375,60 \mathrm{~b}$ & $616,03 \mathrm{~b}$ & $880,83 \mathrm{~b}$ & $1237,08 \mathrm{~b}$ & $1218,35 \quad c$ \\
\hline & \multicolumn{3}{|c|}{ CV1= $15,96 \%$} & \multicolumn{2}{|c|}{ CV2=13,99\%. } \\
\hline & \multicolumn{5}{|c|}{ Área foliar externa à cabeça $\left(\mathrm{cm}^{2}\right)$} \\
\hline E1 $(80$ x 30cm) & $2611,75 \mathrm{a}$ & 3974,50 a & 7809,13 a & $7494,75 \mathrm{a}$ & 7654,63 a \\
\hline E2 $(60 \times 30 \mathrm{~cm})$ & 2623,87 a & 3297,25 a & $4146,50 \mathrm{~b}$ & 6471,25 a & 7390,88 a \\
\hline \multirow[t]{3}{*}{ E3 $(40 \times 30 \mathrm{~cm})$} & 1562,63 a & 2568,00 a & $3070,50 \mathrm{~b}$ & $3132,50 \mathrm{~b}$ & $3452,38 \mathrm{~b}$ \\
\hline & \multicolumn{3}{|c|}{$C V 1=27,12 \%$} & \multicolumn{2}{|c|}{ CV2 $=26,06 \%$} \\
\hline & \multicolumn{5}{|c|}{ Índice de área foliar $\left(\mathrm{cm}^{2} \mathrm{~cm}^{-2}\right)$} \\
\hline $\mathrm{E} 1(80 \times 30 \mathrm{~cm})$ & $1,125 \mathrm{a}$ & $1,650 \mathrm{a}$ & $3,250 \mathrm{a}$ & $3,125 \mathrm{a}$ & $3,200 \mathrm{ab}$ \\
\hline E2 $(60 \times 30 \mathrm{~cm})$ & $1,450 \mathrm{a}$ & $1,825 \mathrm{a}$ & $2,300 \mathrm{a}$ & 3,600 a & 4,125 a \\
\hline \multirow[t]{2}{*}{ E3 $(40 \times 30 \mathrm{~cm})$} & $1,300 \mathrm{a}$ & $2,150 \mathrm{a}$ & $2,550 \mathrm{a}$ & $2,600 \mathrm{a}$ & $2,875 \mathrm{~b}$ \\
\hline & \multicolumn{3}{|c|}{$\mathrm{CV} 1=30,08 \%$} & \multicolumn{2}{|c|}{$\mathrm{CV} 2=25,10 \%$} \\
\hline
\end{tabular}

Dentro de cada característica, médias nas colunas seguidas pela mesma letra, não diferem entre si pelo teste de Tukey a 5\% de probabilidade.

CV1=coeficiente de variação da parcela; CV2=coeficiente de variação da subparcela.

cabeça, a produção de massa fresca de cabeça/área só foi inferior no espaçamento intermediário (E2) com 75 $\mathrm{kg} \mathrm{ha}^{-1}$ de $\mathrm{N}$, indicando que o índice de área foliar que maximiza a eficiência fotossintética para o repolho deve estar próximo de $2,88 \mathrm{~cm}^{2} \mathrm{~cm}^{-2}$.

A precocidade de colheita aumentou com o incremento das doses de $\mathrm{N}$ e do espaçamento, havendo uma redução para os E1 e E2, em média, de 13 dias no ciclo da cultura na maior dose de $\mathrm{N}$, quando comparado à ausência de N (Dados não apresentados). Maiores disponibilidades de espaço e de N, promoveram o crescimento mais rápido das plantas, sobretudo no maior espaçamento (E1), o que concorreu para redução do ciclo da cultura. Alguns autores (HAYNES, 1986; MARSCHNER, 1995; PACHECO, 1996; TORRES, 1999; FILGUEIRA, 2000), afirmam que o excesso de fertilização nitrogenada pode prolongar o ciclo cultural, fato não observado nesse trabalho, talvez em razão da maior dose utilizada ainda não ter se constituído em dose excessiva.
Aumento da precocidade de colheita com diminuição da densidade de plantio também foi verificado para o repolho por Stoffella e Fleming (1990) e em couve-de-Bruxelas por Kirk (1981). O aumento da precocidade pode se constituir em fator decisivo quando o fator ambiente tem grande peso no custo de produção, como o cultivo sob ambiente protegido, que ainda não é o caso da exploração do repolho nas condições brasileiras.

Considerando as doses de $\mathrm{N}$ para máxima eficiência econômica $(95 \%$ da produção máxima) em cada espaçamento, a redução do espaçamento (E3) promoveu aumento de apenas $3,31 \%$ no custo de produção total, quando comparado ao maior espaçamento (E1). Todavia, considerando que no menor espaçamento obteve-se maior percentual de produto com tamanho mais adequado às exigências do consumidor para consumo in natura, portanto alcançando melhores preços de mercado, mesmo com custo de produção mais elevado, o espaçamento de $40 \mathrm{x}$ 
Tabela 2. Análise econômica da produção de repolho em função de espaçamentos, nas respectivas doses de máxima eficiência econômica*. Viçosa, UFV, 2002.

\begin{tabular}{|c|c|c|c|c|c|}
\hline \multirow{2}{*}{\multicolumn{2}{|c|}{$\frac{\text { Custos }}{\text { Produtos/Serviços }}$}} & \multicolumn{4}{|c|}{ Espaçamentos } \\
\hline & & \multicolumn{2}{|c|}{ E1 $(80 \times 30 \mathrm{~cm})$} & $=2(60 \times 30 \mathrm{~cm})$ & E3 $(40 \times 30 \mathrm{~cm})$ \\
\hline & & \multicolumn{4}{|c|}{$\mathbf{R} \$$} \\
\hline \multicolumn{2}{|l|}{ Sementes $^{1}$} & \multicolumn{2}{|c|}{134,46} & 179,82 & 269,78 \\
\hline \multicolumn{2}{|c|}{ Produção de mudas ${ }^{1}$} & \multicolumn{2}{|c|}{155,13} & 210,26 & 310,33 \\
\hline \multicolumn{2}{|c|}{ Preparo do solo } & \multicolumn{2}{|c|}{350,00} & 350,00 & 350,00 \\
\hline \multicolumn{2}{|l|}{ Mão-de-obra ${ }^{1}$} & \multicolumn{2}{|c|}{612,00} & 636,00 & 660,00 \\
\hline \multicolumn{2}{|l|}{ Fertilizantes ${ }^{1}$} & \multicolumn{2}{|c|}{$1.756,00$} & $1.588,00$ & $1.644,00$ \\
\hline \multicolumn{2}{|c|}{ Produtos fitossanitários } & \multicolumn{2}{|c|}{110,00} & 110,00 & 110,00 \\
\hline \multicolumn{2}{|c|}{ Irrigação² } & \multicolumn{2}{|c|}{439,00} & 397,00 & 411,00 \\
\hline \multicolumn{2}{|c|}{ Controle de daninhas ${ }^{2}$} & \multicolumn{2}{|c|}{264,00} & 192,00 & 132,00 \\
\hline \multicolumn{2}{|c|}{ Embalagem + transporte + vendas ${ }^{1}$} & \multicolumn{2}{|c|}{$8.975,00$} & $9.221,60$ & $9.335,00$ \\
\hline \multicolumn{2}{|c|}{ Custos Totais ( $\mathrm{R} \$$ ) } & \multicolumn{2}{|c|}{$\begin{array}{c}12.795,59 \\
(100 \%)\end{array}$} & $\begin{array}{r}12.884,68 \\
(100,7 \%) \\
\end{array}$ & $\begin{array}{l}13.222,11 \\
(103,3 \%) \\
\end{array}$ \\
\hline \multicolumn{6}{|l|}{ Receita } \\
\hline \multirow[t]{2}{*}{ Espaçamento } & $\begin{array}{c}\text { Quantidade } \\
\text { (embalagem } 25 \mathrm{~kg} \text { ) }\end{array}$ & Cotação & $\begin{array}{l}\text { Receita } \\
\text { bruta }\end{array}$ & Custo & Receita líquida \\
\hline & \multicolumn{5}{|c|}{$\mathbf{R} \$$} \\
\hline E1 $(80 \times 30 \mathrm{~cm})$ & 3750 & 5,40 & $20.250,00$ & $12.795,59$ & $7.454,41(100 \%)$ \\
\hline E2 $(60 \times 30 \mathrm{~cm})$ & 4024 & 6,00 & $24.144,00$ & $12.884,68$ & $11.259,32(151 \%)$ \\
\hline E3 $(40 \times 30 \mathrm{~cm})$ & 4150 & 7,20 & $29.880,00$ & $0 \quad 13.222,11$ & $16.657,89(226 \%)$ \\
\hline
\end{tabular}

"Doses de máxima eficiência econômica $\left(285,229\right.$ e $253 \mathrm{~kg} \mathrm{ha}^{-1}$ de N, para E1, E2 e E3 respectivamente).

${ }^{1 /}$ Valores diferem em razão das diferentes quantidades utilizadas em cada espaçamento; ${ }^{2}$ Estimada em $25 \%$ do valor do custo dos fertilizantes; ${ }^{3 /}$ Calculado com base no despendido nas capinas; ${ }^{4 / C}$ Calculado com base em cotações das CEASA-MG, CEASA-RJ e CEAGESP, de acordo com as características do produto.

$30 \mathrm{~cm}$ na dose de $\mathrm{N}$ para máxima eficiência econômica $\left(253 \mathrm{~kg} \mathrm{ha}^{-1}\right)$ resultou em receita líquida $126 \%$ maior do que aquela obtida no maior espaçamento (Tabela 2).

Considerando-se as exigências do mercado consumidor por cabeças menores para consumo in natura, pesando entre 1,0 e $1,5 \mathrm{~kg}$, e os aspectos relacionados com a produção e retorno líquido, o espaçamento E3 $(40$ x $30 \mathrm{~cm})$ é o mais indicado. Para esse espaçamento, a dose de $\mathrm{N}$ de máxima eficiência econômica, indicada é de $253 \mathrm{~kg} \mathrm{ha}^{-1}$ de $\mathrm{N}$ para o cultivo do repolho na primavera.

\section{AGRADECIMENTOS}

Os autores agradecem ao CNPq pela bolsa de iniciação científica concedida ao primeiro autor.

\section{LITERATURA CITADA}

BORA, G.C.; DEKA, B.C.; SHADEQUE, A. Effect of different levels of nitrogen and spacing on head yield of cabbage (Brassica oleraceae convar capitata var capitata). Indian Journal of Agricultural Sciences, v.62, n.8, p.527-528, 1992 CARDOSO, A.I.I.; HIRAKI, H. Avaliação de doses e épocas de aplicação de nitrato de cálcio em cobertura na cultura do rabanete. Horticultura Brasileira, Brasília, v.19, n.3, p.328-331, 2001.

CASTRO, P.R.C.; FERREIRA, S.O.; YAMADA, T. Ecofisiologia da produção agrícola. Piracicaba: Associação Brasileira para Pesquisa da Potassa e do Fosfato, 1987. 249 p.

CHITARRA, M.I.F.; CHITARRA, A.B. Pós-colheita de frutos e hortaliças: fisiologia e manuseio. Lavras: ESAL/FAEPE, 1990. 390 p. FERREIRA, W.R.; RANAL, M.A.; FILGUEIRA, F.A.R. Fertilizantes e espaçamento entre plantas na produtividade da couve-da-Malásia. Horticultura Brasileira, Brasília, v.20, n.4, p.635640, 2002.
FILGUEIRA, F.A.R. Novo Manual de Olericultura: agrotecnologia moderna na produção e comercialização de hortaliças. Viçosa: UFV, 2000. 402 p.

FONTES, P.C.R. Diagnóstico do estado nutricional das plantas. Viçosa: UFV, 2001. 121 p.

HAYNES, R.J. Mineral nitrogen in the plant-soil system. Orlando: Academic Press, 1986. 483 p.

KIRK, S. An investigation into the effects of plant density na time of harvest on yield of Brussels sprouts. Journal of the National Institute of Agricultural Botany, v.15, p.488-496, 1981.

LÉDO, F.J.S.; SOUZA, J.A.; SILVA, M.R. Avaliação de cultivares e híbridos de repolho no Estado do Acre. Horticultura Brasileira, Brasília, v.18, n.2, p.138-140, 2000.

MARSCHNER, H. Mineral nutrition of higher plant. 2.ed. New York: Academic Press, 1995. 889 p.

PACHECO, D.D. Índices de disponibilidade de nitrogênio, teores de nitrato e de vitamina $C$, composição mineral e produção de repolho em resposta a doses de nitrogênio, de composto orgânico e de molibdênio. 1996, 79 f. (Tese mestrado) UFV, Viçosa.

RESENDE, G.M.; SOUZA, R.J. Doses e épocas de aplicação de nitrogênio sobre a produtividade e características comerciais de alho. Horticultura Brasileira, Brasília, v.19, n.2, p.126-129, 2001.

RIBEIRO JÚNIOR, I.R. Análises estatísticas no SAEG. Viçosa: UFV, 2001. 301 p.

RIBIRO, A.C.; GUIMARÃES, P.T.G.; ALVAREZ, V.H. Recomendações para o uso de corretivos e fertilizantes em Minas Gerais: $5^{a}$ aproximação. Viçosa: Comissão de fertilidade do solo do estado de Minas Gerais, 1999. 35 p.

SILVA JÚNIOR, A.A. Repolho: fitologia, fitotecnia, tecnologia alimentar e mercadológica. Florianópolis: EMOASC, 1987. 259 p.

SILVA JÚNIOR, A.A.; MIURA, L.; YOKOYAMA, S. Repolho: novas cultivares de verão. Agropecuária Catarinense, Florianópolis, v.1, n.3, p.47-49, 1988.

SILVA, V.F.; NETO, F.B.; NEGREIROS, M.Z.; PEDROSA, J.F. Comportamento de cultivares de alface em diferentes espaçamentos sob temperatura e luminosidade elevadas. Horticultura Brasileira, Brasília, v.18, n.3, p. 183-187, 2000.

STOFFELLA, P.J.; FLEMING, M.F. Plant population influences yield variability of cabbage. Journal of the American Society of Horticultural Science, v.115, p.708-711, 1990.

TAIZ, L.; ZEIGER, E. Plant physiology. Redwood City, Califórnia: The Benjamin/Cummings Publising Company, 1991. 559 p.

THOMPSON, R.; TAYLOR, H. Plant competition and its implications for cultural methods in calabrese. Journal of Horticultural Science, v.51, p.230-231, 1976.

TORRES, A.N.L. Produção e qualidade de variedades de repolho e cenoura. 1999. 72 f. (Tese mestrado) - UFV, Viçosa. 